\title{
QUANDO A VOZ RESSOA NA LETRA: CONCEITOS DE ORALIDADE E FORMAÇÃO DO PROFESSOR DE LITERATURA
}

\author{
Vera Lúcia Cardoso Medeiros*
}

RESUMÉE: d'aprés les ouevres Oralidade e cultura escrita, de Walter Ong, Introdução à poesia oral_et $A$ letra e a voz, de Paul Zumthor, cet article présente les caractéristiques de la pensée et du langage produits dans les cultures d'oralité primaire. Il presente aussi les marques de la voix au texte écrit, surtout le littéraire. À la fin, on fait une reflexion sur l'importance d'oralité à la formation du professeur de litterature.

PALAVRAS-CHAVE: oralidade; voz; literatura; escrita; professor de literatura.

\section{Apresentação}

Este texto surge de algumas inquietações referentes à formação de leitores do texto literário e de professores de literatura. É de largo conhecimento a dificuldade que estudantes - tanto do nível fundamental e médio quanto do ensino superior - apresentam ante o texto escrito e especialmente o literário. Entretanto, todos - crianças, jovens ou adultos - silenciam e escutam com atenção e prazer histórias, causos e anedotas recitadas na sala de aula pelo professor ou pelos colegas. Contar oralmente é mais natural do que escrever; ouvir prende mais a atenção do que ler: essas situações são freqüentemente expressas pelos alunos ou observadas pelos professores.

Essa necessidade de contar ou ouvir antes de ler e escrever remete à origem do que se entende atualmente por literatura. No começo de tudo, antes do verbo e do texto escrito, havia a voz, como indicam, por exemplo, A Ilíada e A Odisséia, surgidas como canto entoado por várias gerações até serem fixadas pela escrita. Assim, as relações entre voz e letra, oralidade e escrita foram e são tão íntimas quanto complexas e problemáticas, qualidades que se intensificam em função das novas formas de oralidade surgidas com as constantes transformações tecnológicas.

Apesar dos antigos e fortes elos entre oralidade e literatura, a escola e a universidade constituem-se como espaços de expressão escrita em que a oralidade é pouco valorizada e o passado comum entre letra e voz é quase totalmente esquecido. Será que o lugar, ou melhor, o não-lugar da oralidade na escola não estará ligado a um certo insucesso no processo de formação de leitores do texto literário? É em torno dessa questão que se constrói o presente texto, no qual serão apresentados conceitos que procuram definir voz, oralidade, escrita e literatura para posteriormente examinar as marcas que a voz imprime à letra e a necessidade de essa discussão integrar os programas dos cursos de letras para, assim chegar ao ensino fundamental e médio.

\section{Mapeando conceitos}

Os conceitos que hoje são considerados fundamentais nos estudos da literatura oral remontam ao princípio da década de 1980 e foram formulados por Walter Ong e Paul Zumthor. É claro que, além desses dois, há muitos outros pesquisadores do tema, mas eles foram responsáveis por estudos de fôlego que têm permitido pensar nas peculiaridades da oralidade diante da escrita e nas relações entre ambas, caracterizar o pensamento que se fundamenta em cada uma dessas modalidades de comunicação e, por fim, definir o que por ora se está designando como 'literatura oral', abrindo assim caminho para muitos outros que lhes seguiram os passos fundamentados em suas constatações e terminologia.

Em 1982, o padre jesuíta Walter Ong publica Orality e literacy. The technologizing of the Word, que, em português, teve o título de Oralidade e cultura escrita. Em seus estudos, Ong retoma Mc Luhan para tratar de escrita e oralidade desde tempos remotos até chegar na era da mídia eletrônica. Já o suíço Paul Zumthor

\footnotetext{
* Professora de Literatura Brasileira, Portuguesa e Literaturas de Língua Portuguesa nas Faculdades PortoAlegrenses.
} 
dedica-se ao embricamento entre letra e voz a partir de textos medievais e traça ampla caracterização do que denomina poesia oral ou poética da voz principalmente em Introduction à la poésie orale, de 1983, e La lettre et la voix, de $1984^{1}$. Os estudos de Zumthor tratam mais diretamente das articulações entre oralidade e literatura, enquanto que Ong não aborda especificamente a questão literária, enfocando a escrita de modo genérico.

\section{Pensamento e expressão em culturas de oralidade primária}

Um mapa conceitual relativo à 'literatura oral' pode principiar pelas expressões oralidade primária e oralidade secundária. Atualmente vive-se tão imerso no universo da escrita que quase não se concebe cultura formada e preservada sem nenhum apoio de textos, documentos, cartas, relatórios escritos. Walter Ong denomina de culturas de oralidade primária as que se definem por desconhecerem a escrita ou impressão gráfica e culturas de oralidade secundária aquelas em que a expressão e a criação dependem da escrita e da impressão, e a comunicação oral apóia-se na alta tecnologia - rádio, telefone, televisão.

Ainda que hoje inexistam, no sentido estrito, comunidades de cultura oral primária, Ong lembra que a escrita não pode prescindir da oralidade, mas, ao contrário, a “... expressão oral pode existir - e na maioria das vezes existiu - sem qualquer escrita...” (ONG, 1998, p. 16), de modo que nossos vínculos com a expressão oral são ancestrais e intensos, fazendo-se notar na relação com a escrita e seus produtos, como depreende-se do seguinte trecho:

... a despeito dos mundos maravilhosos que a escrita abre, a palavra falada ainda subsiste e vive. Todos os textos escritos devem, de algum modo, estar direta ou indiretamente relacionados ao mundo sonoro, habitat natural da linguagem, para comunicar seus significados. "Ler" um texto significa convertê-lo em som, em voz alta ou na imaginação, sílaba por sílaba na leitura lenta ou de modo superficial na leitura rápida, comum a culturas de alta tecnologia. (ONG, 1988, p. 16)

E por que tendemos a transformar a palavra espacializada através da escrita em voz ? Talvez porque nossa mais remota lembrança de um ato de comunicação esteja ligada à voz, afinal comunicamos nosso nascimento com ela - o primeiro choro. Por outro lado, é comum representar a morte pelo último grito ou pelas últimas palavras. Sob essa perspectiva, pode-se afirmar que a expressão oral - ou vocal - está presente no início e no fim da existência humana, e o que a voz simboliza nessas representações de vida e morte - o primeiro choro ou as últimas palavras - é a interação do sujeito com o outro. Enquanto há palavra (voz), há vida; antes do primeiro choro (voz), não se nasce para o outro.

Seguindo essa perspectiva, constata-se que uma das características fundamentais da oralidade está ligada a seu caráter de exterioridade e de vivência coletiva. "Palavras ditas ao vento" são inúteis, ensina a sabedoria popular, já que a voz que ressoa precisa ser ouvida para cumprir seu destino. Assim sendo, uma cultura marcada pela oralidade é também uma cultura que preza a experiência coletiva, enquanto que a escrita tende a criar uma situação de maior isolamento entre os indivíduos.

No capítulo "Sobre a psicodinâmica da oralidade", o terceiro de Oralidade e cultura escrita, Walter Ong demora-se em apontar as peculiaridades do pensamento estruturado em sociedades de oralidade primária. Nessas comunidades, a palavra é apenas som, já que não ganha a forma escrita, o qual sempre exerce um poder. Ong então refere Malinowski ao lembrar que "a linguagem é um modo de ação e não simplesmente uma confirmação do pensamento" (ONG, 1988, p. 42) e que o som é dotado de poder e potencialidade mágica.

$\mathrm{Na}$ cultura que se forja assim, pela expressão oral, os processos mentais desenvolvem-se de modo muito diferente dos encontrados na cultura escrita. Ong menciona que, no universo da escrita, para saber ou adquirir conhecimento, precisamos estudar - e estudar aqui passa necessariamente pela leitura e pela escrita. Os integrantes de comunidades de oralidade primária, por motivos óbvios, conheciam e sabiam sem o apoio do texto.

\footnotetext{
${ }^{1}$ Há evidentemente outros estudos importantes acerca das particularidades da oralidade e de suas relações com a escrita que serão citados e comentados ao longo deste artigo, ainda que não tenham sido examinadas com o mesmo detalhamento com que foram os trabalhos de Ong e Zumthor. Também não se procedeu a uma análise comparativa e contrastiva desses autores.
} 
Na oralidade primária, é necessário que exista um interlocutor virtual, já que não há, fora do sujeito que pensa, nada que lhe permita recuperar o raciocínio desenvolvido. Percebe-se, portanto, que "o pensamento apoiado em uma cultura oral está preso à comunicação" (ONG, 1988, p. 44), que implica a presença daquele que fala e daquele com quem ou a quem fala em uma situação de performance, definida por Paul Zumthor como coincidência de comunicação e recepção no tempo. Lembremos que, na escrita, a comunicação não se faz mediante a coincidência temporal entre produção e recepção; aliás, ela serve para que $\mathrm{o}$ ato comunicativo se dê sem que emissor e receptor estejam face a face.

A presença do interlocutor, entretanto, não basta para reter o pensamento que se esboça sem o aporte da escrita. É necessário "pensar pensamentos memoráveis" (ONG, 1988, p. 45), que podem ser retidos, recuperados e repetidos. Esses pensamentos são obtidos a partir de padrões que permitem a repetição oral, ou seja, padrões rítmicos - o ritmo é altamente memorável -, equilibrados, nos quais se façam presentes repetições, antíteses, aliterações, assonâncias, expressões epitéticas ou formulares, provérbios, todos esses recursos que favorecem a memorização do pensamento e sua repetição.

Caracteriza também o pensamento das culturas orais primárias o predomínio de estruturas aditivas em lugar das subordinativas, fato que se torna evidente quando se observam produções verbais orais. As estruturas aditivas facilitam a retenção da frase ou verso na memória do falante ou do ouvinte, bem como permitem que se façam acréscimos ao canto ou narrativa original. Ong lembra que "as estruturas orais muitas vezes consideram a pragmática (a conveniência do falante)", ao passo que "as estruturas quirográficas ${ }^{2}$ levam mais em conta a sintaxe (organização prática do discurso)" (ONG, 1988, p. 48), ou seja, a organização de pensamento e linguagem em culturas de oralidade primária prioriza o sujeito que se comunica - o emissor da mensagem -, enquanto que o código e sua organização mobilizam as formas de pensar e estruturar a linguagem onde a escrita domina.

Outra marca do pensamento e da linguagem fundados na oralidade é que eles são mais agregativos do que analíticos. Isso para, mais uma vez, facilitar o trabalho da memória. O trecho a seguir explica como Ong entende esse traço:

As nações orais preferem, especialmente no discurso formal, não o soldado, mas o soldado valente; não a princesa, mas a bela princesa; não o carvalho, mas o carvalho robusto. Assim a expressão oral está carregada de uma quantidade de epítetos e outras bagagens formulares que a cultura altamente escrita rejeita como pesados e tediosamente redundantes em virtude de seu peso agregativo. (ONG, 1988, p. 49)

Vale destacar, a partir do trecho acima, que um mesmo traço - caracterização excessiva - é qualidade para as culturas orais e defeito para as escritas, provando que narrativas orais não podem ser examinadas pelos mesmos parâmetros utilizados para narrativas produzidas pela cultura da letra e da impressão.

A necessidade de dar continuidade ao pensamento e à expressão explica porque, nas oralidades primárias, eles são redundantes ou copiosos. Na escrita, lembra Ong, a linha garante que o pensamento não se perca; contudo, no discurso oral a situação é outra:

Não há nada para retroceder fora da mente, pois a manifestação oral desapareceu tão logo foi pronunciada. Por conseguinte, a mente deve avançar mais lentamente, mantendo perto do foco de atenção muito daquilo com que já se deparou. A redundância, a repetição do já dito, mantém tanto o falante quanto o ouvinte na pista certa. (ONG, 1988, p. 50)

A necessidade da presença do interlocutor e de formular pensamentos que possam ser recuperados facilmente pela memória, o predomínio de estruturas aditivas e de pensamentos agregativos e redundantes, características destacadas por Walter Ong como próprias das culturas de oralidade primárias e até aqui foram apresentadas, relacionam-se a aspectos formais ou objetivos do pensamento e da expressão a ele associada. Mas Ong identifica outros traços, os quais estão ligados a questões associadas ao tema ou à natureza do pensamento que se expressa através da expressão oral.

\footnotetext{
${ }^{2}$ Em Oralidade e cultura escrita, Walter Ong refere-se à cultura quirográfica como aquela que tem algum tipo
} de escrita e cultura tipográfica é a que utiliza a escrita impressa. 
O tradicionalismo ou conservadorismo está entre essas características ligadas ao tema. Sem o suporte escrito, a preservação de um conteúdo através da memória é algo bastante trabalhoso, motivo que estabelece "uma conformação mental altamente tradicionalista ou conservadora, que, compreensivelmente, inibe o experimento intelectual" (ONG, 1988, p. 52). Essa qualidade do pensamento ligado à oralidade determina o respeito que o sábio ancião inspira nas comunidades tradicionais de oralidade primária.

Embora haja a tendência ao tradicionalismo, não falta originalidade às produções nas culturas orais. Os narradores introduzem novos elementos a velhas histórias, criam diferentes versões de um mito e buscam situações singulares que levem o público a reagir. Portanto, a originalidade dá-se através da remodelação de fórmulas e temas mais do que por meio de sua substituição.

Fatos do cotidiano inspiram o pensamento em meio à oralidade primária, como revela mais esta passagem de Oralidade e cultura escrita:

Na ausência de categorias analíticas aperfeiçoadas, que dependem da escrita para organizar o conhecimento distante da experiência vivida, as culturas orais conceituam e verbalizam todo o seu conhecimento como uma referência mais ou menos próxima ao cotidiano da vida humana, assimilando o mundo estranho, objetivo, à interação imediata, conhecida de seres humanos.(ONG, 1988, p. 53)

Narrativas, poemas, canções e outros produtos artísticos concebidos em ambientes de predomínio do oral facilmente atestam mais essa característica apontada por Walter Ong. O trabalho, as fases da vida, as necessidades prementes do ser humano, os medos, as alegrias e esperanças servem de inspiração ao cantor e narrador. Mesmo os enredos envolvendo seres misteriosos ou sobrenaturais estão próximos, no telhado, no fundo do rio, no sótão da igreja. Através da voz, os sujeitos tratam de suas comunidades e de suas vidas diárias com objetividade, desviando-se de pensamentos abstratos ou que não digam respeito a experiências ou emoções vividas pelo grupo.

Ligado a esse tipo de característica, que se volta para seu aqui e agora - o cotidiano -, está um outro traço marcante das sociedades orais, que é elas viverem "preponderantemente num presente que se mantém em equilíbrio ou homeostase, descartando-se de memórias que já não são relevantes para esse presente" (ONG, 1988, p. 58). Conserva-se do passado o que é significativo para a sociedade no seu estágio atual; o que não faz parte da experiência presente é alterado. Ong exemplifica essa característica comentando a situação das palavras e a existência de dicionários, que preservam os vários sentidos de um termo através do tempo, mesmo os que caíram em desuso. De forma diferente, onde predomina a oralidade, interessam somente os significados da palavra empregada na vida real e contemporânea.

As palavras adquirem significados somente de seu hábitat real sempre constante, que não consiste meramente, como num dicionário, em outras palavras, mas inclui também gestos, inflexões vocais, expressão facial e todo o cenário humano e existencial em que a palavra real, falada, sempre ocorre. Os significados da palavra nascem continuamente do presente, embora os significados passados obviamente tenham moldado o significado presente em muitos e diferentes aspectos, já não reconhecidos. (ONG, 1988, p. 58)

Eis outra peculiaridade que pode receber tratamento diferente nas culturas de oralidade primária e nas culturas escritas. Nestas, a palavra impressa concentra toda a significação e, pelo contexto do escrito, depreende-se seu sentido. Na palavra dita, o sentido tem que ser percebido imediatamente, para o que concorrem elementos não-verbais que constituem a situação de performance em que todo ato de oralidade se concretiza.

Essa vida próxima e presente, real, é feita de luta, por isso o tom agonístico é identificado por Ong como mais uma característica do pensamento e da expressão orais. As abstrações favorecidas pela escrita geram um conhecimento distante da "arena onde os seres humanos lutam entre si" e "separa aquele que conhece daquilo que é conhecido", ao contrário, "ao manter o conhecimento imerso na vida cotidiana, a oralidade o situa dentro de um contexto de luta” (ONG, 1988, p. 55). Provérbios e enigmas são apontados 
como meios de expressar esse caráter de luta que a vida adquire quando é expressa calcada na realidade. O tom agonístico explicaria as descrições de violência física encontradas em muitas narrativas orais.

Ainda referente à importância atribuída pelas culturas orais ao que está próximo no tempo e no espaço está a tendência de o pensamento ser mais situacional do que abstrato. Mesmo que todo pensamento conceitual exija um certo nível de abstração, as culturas orais buscam empregar conceitos minimamente abstratos e próximos do cotidiano.

Concluindo esse levantamento de marcas do pensamento e da linguagem originados em culturas de oralidade primária, está a tendência para a empatia e a participação. Retomando Havelock, também estudioso das relações entre escrita e oralidade, Ong afirma que "para uma cultura oral, aprender ou saber significa atingir uma identificação íntima, empática, comunal com o conhecido..." (ONG, 1988, p. 57), contrariamente ao que se passa nas culturas em que predomina a escrita, as quais, ao separar conhecedor e conhecido, criam a objetividade, que implica desprendimento e distanciamento.

Sintetizando o que até aqui foi apresentado, pode-se afirmar que culturas de oralidade primária fundamentam-se em pensamento e linguagem estruturados a partir de meios que permitem memorizar o conhecido, objetivo atingido por meio de distintas maneiras de repetição e reiteração, e tratam ou remetem ao próximo no tempo e no espaço, gerando um sentimento de pertença à comunidade na qual o ouvinte ou interlocutor tem a mesma importância que o narrador, cantador, contador ou aquele que profere as palavras.

As características da oralidade tornam evidentes suas diferenças em relação à escrita e mostram que essas formas de expressão, às quais correspondem modos diferentes de estruturação de pensamento, representam igualmente dois tipos de civilização. Mc Luhan foi o ponto de partida dos estudos de Walter Ong, que, segundo Paul Zumthor, aprofundou o que naquele estava apenas esboçado. Zumthor, por sua vez, em Introdução à poesia oral, também recorre a Mc Luhan para estabelecer distinções entre oralidade e escrita, em trecho que a seguir vai citado:

Assim, na perspectiva Mc Luhaniana, da oralidade à escrita se opõem globalmente dois tipos de civilização. Em um universo de oralidade, o homem, diretamente ligado aos ciclos naturais, interioriza, sem conceituá-la, sua experiência da história; ele concebe o tempo segundo esquemas circulares, e o espaço (a despeito de seu enraizamento), como a dimensão de um nomadismo; as normas coletivas regem imperiosamente os seus comportamentos. Em compensação, o uso da escrita implica uma disjunção entre o pensamento e a ação, um nominalismo natural ligado ao enfraquecimento da linguagem como tal, a predominância de uma concepção linear do tempo e cumulativa do espaço, o individualismo, o racionalismo, a burocracia...(ZUMTHOR, 1997, p. 36)

\section{Poética da voz}

Até aqui foi utilizada a expressão 'literatura oral' em referência à criação artística e verbal produzida oralmente sem contar com a escrita como suporte principal. Agora é o momento de tratar dessa questão terminológica.

Em Oralidade e cultura escrita, Ong considera monstruoso e absurdo o termo 'literatura oral', criado em 1881 por Paul Sébillot. Mas, como não focaliza especificamente a questão literária - seu enfoque é mais amplo -, ele não propõe uma outra denominação.

Quem se dedica a esse aspecto é Paul Zumthor, que se debruça sobre a literatura medieval e, portanto, lida com corpus formado de textos escritos produzidos em contexto de passagem da oralidade à escrita. Inicialmente ele propõe o emprego da expressão 'poesia oral', mais restrita, em sua opinião, do que 'literatura oral', forma vaga que pode significar

.entre os etnólogos, um tipo de discurso com finalidade sapiencial ou ética; e, num sentido amplo, entre os raros historiadores da literatura interessados por estes problemas, todos os tipos de enunciados metafóricos ou ficcionais que ultrapassam o valor de um enunciado entre indivíduos: contos, jogos verbais infantis, facécias e outros discursos tradicionais... (ZUMTHOR, 1997, p. 48) 
A 'poesia oral', segue Zumthor, é “... formalizada mais rigorosamente e provida de indícios de estruturação mais evidentes” (ZUMTHOR, 1997, p. 48), causando-lhe a impressão de que ela, mais do que o conto, adere "ao que a existência coletiva comporta de mais repetitivo a nível profundo; daí uma redundância particular e uma variedade mínima nos temas" (ZUMTHOR, 1997, p. 48). Para o estudioso, 'poesia' ou 'poética' são termos que preservam conotação criativa e artística que não está assegurada na palavra 'literatura', a qual traz em sua raiz a idéia de letra e, por conseguinte, de escrita.

Em A letra e a voz, o autor manifesta a preferência pelo termo vocalidade: "à palavra oralidade prefiro vocalidade. Vocalidade é a historicidade de uma voz: seu uso" (ZUMTHOR, 1993, p. 21), e a voz possui qualidades materiais como tom, timbre, altura e registro, espessura concreta e a "tactilidade do sopro", ensina Zumthor. Enfim, nas palavras vocalidade e voz há materialidade e concretização - aspectos que não se aplicam ao vocábulo oralidade - mesmo quando essa voz está desprovida de linguagem ou de palavra, esta última definida como "a linguagem vocalizada, realizada fonicamente na emissão da voz" (ZUMTHOR, 1997, p. 13) e realiza-se apenas como som.

Para sustentar sua opção terminológica, Zumthor lembra que expressões de sentimentos intensos, como o murmúrio ou o riso, provocam o uso não da linguagem, ou seja, da palavra, do som organizado em estruturas mínimas significativas, mas, as fortes emoções são comunicadas através da voz, atributo que o ser humano dispõe desde o nascimento e através do qual pode naturalmente expressar-se.

Com base em tais argumentos é que Paul Zumthor adota a expressão poesia ou poética da voz, a qual seria mais específica e menos comprometida com enfoques redutores e generalistas do que 'literatura oral'3. Por concordarmos com as considerações feitas por Zumthor, passamos a utilizar poesia ou poética (s) da voz para designar a criação artística verbal que se produz e preserva oralmente ou que guarda características desse tipo de criação.

\section{Marcas da voz na letra}

Em Zumthor, o estudo da voz decorre de pesquisas sobre a literatura medieval, pois ela, por evidentes razões cronológicas, mantém sinais claros de períodos em que a escrita era de domínio bastante restrito, o que favorecia as criações eminentemente orais. Vale transcrever trecho de A letra e a voz em que ele fala desse período.

.na aurora do mundo saído da desagregação das culturas grecoromanas, e durante os próprios séculos em que se restabelecia pouco a pouco o equilíbrio das forças civilizadoras, manteve-se e desenvolveu-se uma arte vocal original. Tanto as reações indignadas do alto clero quanto o uso folclorista que dela fizeram os poetas da corte, a partir do século XIII, atestam sua irredutibilidade e sua longa fecundidade. As obras dessa arte estão para nós irremediavelmente perdidas. Percebemos apenas seus reflexos. Mas existiram; no seio de uma tradição viva, sucederam-se durante toda a época merovíngia e carolíngia, a época feudal mais recuada. É historicamente bem improvável que tal experiência não tenha marcado, muito tempo ainda depois desse prazo, toda a poesia - não tanto nas formas de linguagem nem nos motivos imaginários, mas num nível profundo, na experiência de certo acordo entre o verbo e a voz. (ZUMTHOR, 1993, p. 51)

No final da passagem acima transcrita, está a motivação da pesquisa desenvolvida por Zumthor: os escritos literários medievais que chegaram a nosso conhecimento guardaram resquícios de oralidade determinantes de características denunciadoras das marcas que a voz deixa na letra. Passaremos, a seguir, a verificar essas características, que constantemente remeterão ao estudo feito por Walter Ong, já examinado neste artigo, sobre as peculiaridades da expressão e do pensamento em comunidades de oralidade primária.

\footnotetext{
${ }^{3}$ Neste artigo, será adotada a expressão "poética da voz" para designar criações verbais em prosa ou em verso que não têm na escrita o único ou principal suporte. Já a expressão "marcas da voz" substitui "marcas de oralidade'.
} 
Impõe-se aqui mencionar que Zumthor classifica as relações entre forma escrita e oral em três grupos: há uma oralidade primária, em que não ocorre contato com a escrita; uma oralidade mista, na qual a escrita influencia-a de modo externo, parcial ou retardado ou em que a oralidade é (re) composta através da escrita; no terceiro grupo, ele coloca a oralidade mecânica ou tecnologicamente mediatizada.

A literatura medieval, objeto das pesquisas que fornecem os elementos que serão apresentados a seguir, é produzida em meio a uma dinâmica de oralidade mista, isto é, voz e letra convivem em diferentes graus de interação. De acordo com Zumthor, essa arte estava baseada em "técnicas do encaixe, da combinação, da colagem" (ZUMTHOR, 1993, p. 23), não demonstrava preocupação em demarcar autoria individual nem em singularizar a criação, e registros visuais e táteis eram mal diferenciados. Rupturas de estilo e de tom, heterogeneidades sintáticas experimentação verbal são ainda características dos textos escritos que são influenciados por formas de oralidade.

Zumthor examina atentamente os índices de oralidade dos textos medievais e fornece amplo instrumental para que sejam identificadas as marcas da voz na produção literária escrita. Ele percebe "energias que transbordam do texto" (ZUMTHOR, 1993, p. 207) e as organiza em eixos distintos ${ }^{4}$. Qualidades sintáticas e lexicais integram o eixo que ele considera mais trivial e menos decisivo. Integram esse eixo a justaposição de elementos que não se subordinam; afirmações breves entrecruzadas de exclamações, expressões imperativas e séries cumulativas descontínuas; predomínio de formas nominais sobre as verbais; vocabulário restrito e condensado, provocando inclusive um obscurecimento do sentido; certa vulgaridade de tom que contribui para impressão de conversa ou confissão.

O segundo eixo de indícios de oralidade no texto refere-se à articulação entre sintaxe e retórica. Ele é notado quanto "ao uso dos tempos verbais e aos jogos de mascaramento ou de perspectiva que ele permite" (ZUMTHOR, 1993, p. 208). Enquanto o texto apresenta deslocamentos, descompassos ou contradições aparentes, o emprego de verbos no presente assegura "a permanência de uma palavra-testemunha" e a permanência da "... instância da enunciação, a presença carnal e a continuidade da voz." (ZUMTHOR, 1993, p.208). Ainda nesse segundo eixo estão interrogações, exclamações, travessões e apóstrofes, marcas impressas que denunciam aquilo que, na situação performática, é expresso por meio da entonação, dos gestos, da mímica, enfim, marcas do corpo que se expressa.

O último grupo de características presentes no texto escrito em função de vestígios da presença da voz é tratado por Zumthor como temático e relaciona-se aos elementos que fazem da voz e suas implicações assuntos da escrita, como sugere a próxima citação: " Um motivo referente à palavra, ao som ou ao efeito da voz, ao poder do verbo pronunciado, introduz-se e mantém-se no tecido textual" (ZUMTHOR, 1993, p. 212).

No plano lexical, a voz enquanto tema da escrita é notada na recorrência do que o autor denomina 'verbo de palavra' - dizer, falar, contar - e de fórmulas associadas - quero dizer, digo, direi. Segundo ele, "o emprego da dupla dizer-ouvir tem por função manifesta promover (mesmo ficticiamente) o texto ao estatuto do falante e de designar sua comunicação como uma situação de discurso in praesentia" (ZUMTHOR, 1993, p. 39). Mais adiante lemos que "quaisquer que sejam o conteúdo e a função do texto, somos assim, de todo o lado e de toda a maneira, remetidos à modalidade vocal-auditiva de sua comunicação" (ZUMTHOR, 1993, p. 41). Esses traços dizem respeito à performance, que Zumthor define a circunstância em que se confrontam locutor, destinatário e circunstâncias.

É oportuno perceber que verbos e expressões 'de palavra' que lembram situações de comunicação oral são localizados não apenas em textos literários medievais, mas todas as épocas, incluindo a contemporânea, oferecem exemplos de seu emprego, atestando que as marcas de oralidade na escrita não se restringem ao passado longínquo.

Outro traço mencionado tanto em A letra e a voz quanto em Introdução à poesia oral é a fragmentação do texto transmitido pela voz, que impede sua saturação, constata Zumthor. Na escrita, isso se

\footnotetext{
${ }^{4}$ Em Introdução à poesia oral, livro publicado em 1983, antes, portanto, de A letra e a voz, de 1987, Zumthor apresenta nomenclatura e conceituação um tanto diversas desses eixos. Na obra de 83, ele apresenta quatro grupos de marcas deixadas pela voz deixa no texto escrito. Existem as marcas anedóticas, em que "um texto composto para leitura contém, em forma de citação, um outro texto apresentado como empréstimo à tradição oral"; as marcas formais "que resultam de procedimentos estilísticos supostamente ligados ao uso da voz"; as alusões a acontecimentos que remeteriam a circunstâncias de transmissão oral, essas marcas tratadas pelo autor como problemáticas; o último grupo é o das marcas que fazem induzir que um determinado gênero ou texto surgiu na tradição oral. Escolhi detalhar e empregar a classificação apresentada em A letra e a voz, de 1987, dá-se porque ela pareceu-me uma síntese aperfeiçoada do que Zumthor esboçou em 1983.
} 
manifesta através de formas como aforismos ou rapsódia e também indica que "o texto se prepara para entrar em performance, para integrar-se no movimento de um corpo, em sua verdade vivida, ao abrigo de todo seqüestro racional" (ZUMTHOR, 1993, p. 162).

Todos os elementos arrolados até aqui autorizam a distinguir a estética do contador da estética do autor $^{5}$ e impedem que os textos marcados pela oralidade sejam relegados a uma condição subalterna em relação à literatura escrita e impressa. Eles, pelo contrário, indicam que textos produzidos em contextos diferentes não podem ser analisados a partir dos mesmos instrumentos. Características como redundância, reiteração, justaposição de elementos ou vocabulário familiar podem ser analisadas como defeitos se forem empregados parâmetros prescritos pela cultura escrita ou como qualidades caso sejam consideradas suas funções no âmbito da cultura oral.

Ocupado com formas literárias que preservam traços de oralidade, Zumthor sabe do preconceito com que o universo das letras trata da voz. Narrativa e poesia oral são vistas como produtos do folclore e da cultura popular, sendo tratadas, portanto, como inferiores em relação à escrita. Entretanto, "é inútil julgar a oralidade de modo negativo, realçando-lhe os traços que contrastam com a escritura. Oralidade não significa analfabetismo, o qual, despojado dos valores próprios da voz e de qualquer função social positiva, é percebido como uma lacuna" (ZUMTHOR, 1997, p. 27). Há uma série de qualidades associadas à presença da voz que precisam ser resgatadas, e a manutenção de certos rituais - ou situações performáticas - como defesas públicas e orais de teses, depoimentos, testemunhos, pronunciamentos jurídicos ou políticos são reflexos do poder que a palavra proferida ainda tem. A situação de diálogo, debate e conversa pressupõe a existência de dois elementos, o locutor e o ouvinte, ambos fundamentais ao sucesso do ato comunicativo, ambos alçados à posição de sujeito.

\section{A voz , a escola e a aula de literatura}

Atualmente a oralidade experimenta novas configurações e possui recursos tecnológicos que asseguram sua circulação. Na década de 1980, quando escreveu os textos aqui apresentados, Paul Zumthor já percebia que a oralidade mediatizada foi destituída de seus traços definidores, passando a figurar como um produto da cultura de massa. Concebida por uma tradição erudita escrita e elitista, essa nova oralidade conta com a indústria e o comércio para sua realização e produção, o que limita a espontaneidade da voz e origina novos tipos de vínculos coletivos, geradores de ".socialidade de síntese, agindo sobre elementos separados e fragmentados dos grupos estruturados tradicionais” (ZUMTHOR, 1997, p. 29).

Uma das maiores qualidades da oralidade, sua capacidade de tornar todos os envolvidos em sujeitos do ato de comunicação, desaparece porque é colocada no ar uma voz que não permite resposta, voz que se despersonaliza e perde a vocação comunitária. Segue abaixo trecho de Introdução à poesia oral que lista outras modificações determinadas pela mediatização da voz.

A mobilidade espacial e temporal da mensagem aumenta a distância entre sua produção e seu consumo. A presença física do locutor se apaga; permanece o eco fixo da sua voz e, na televisão e no cinema, uma fotografia. O ouvinte, ao escutar a emissão, está inteiramente presente, mas, no momento da gravação, ele era apenas uma figura abstrata e estatística. (...) Quanto à mensagem, na condição de objeto, ela se fabrica, se expande, se vende, se compra, idêntica em toda parte. Entretanto, não é um objeto que tocamos, pois os dedos do comprador só seguram o instrumento transmissor: disco, fita. Restam apenas os sentidos envolvidos na percepção à distância - a audição - e, quanto ao cinema e à televisão, a visão. Produz-se, assim, uma defasagem, um deslocamento do ato comunicativo oral. (ZUMTHOR, 1997, p. 29-30)

Há algumas atualizações a fazer na passagem acima, concebida há mais de duas décadas. Nada, entretanto, que altere a essência das constatações de Zumthor. A oralidade que se produz a partir dos vários

\footnotetext{
5 Zumthor menciona comentário de O. Jodogne sobre Enéias, na página 211 de A letra e a voz, quando trata especificamente da estética do romancista. Parece-me possível ampliar a abrangência da expressão e remetêla a todos os gêneros textuais escritos.
} 
equipamentos disponíveis atualmente separa quem fala daquele que ouve, eliminando, então, a situação de performance, quando todo corpo comunica junto com a voz. Outra característica da voz propagada via tecnologia é que os envolvidos no ato de comunicação deixam de ser sujeitos desse ato, alterando significativamente, portanto, a natureza dessa modalidade de expressão natural à condição humana.

É bom lembrar que, assim como a oralidade não desapareceu com o fortalecimento e predomínio das culturas quirográfica e impressa, certos traços que lhe definem também podem sobreviver às modificações impostas pela indústria cultural. Então, embora o universo de oralidades primárias esteja muito distante no tempo, ainda temos na voz o meio mais espontâneo e natural de expressão, para o bem ou para o mal do indivíduo.

Em contexto no qual a forma dominante e privilegiada de expressão é a escrita, oralidade é sinônimo de popular ou folclórico, e o lugar que a manifestação da voz tem na escola, de forma geral, denuncia essa posição subalterna.

A escola de hoje é lugar de aquisição e aprimoramento da escrita, tornando-a muito distinta do ambiente doméstico e familiar em função da precária formação cultural e do domínio dos meios de comunicação de massa. Cria-se uma dicotomia entre o mundo da escola - em que se aprende e se mostra o aprendizado via palavra escrita - e o mundo fora da escola - onde a voz que se ouve no telefone móvel, no aparelho de som, na televisão e mesmo nos 'games' e nas 'salas de bate-papo' ${ }^{6}$ acessadas pelos microcomputadores impera. Constata-se, uma vez mais, que a escrita não é a forma natural de expressão humana, como lembra Ong no seguinte excerto:

Um conhecimento mais profundo da oralidade primitiva ou primária permite-nos compreender melhor o novo mundo da escrita, o que ele verdadeiramente é e o que os seres humanos funcionalmente letrados realmente são: seres cujos processos de pensamento não nascem de capacidades meramente naturais, mas da estruturação dessas capacidades, direta ou indiretamente, pela tecnologia da escrita. Sem a escrita, a mente letrada não pensaria e não poderia pensar como pensa, não apenas quando se ocupa da escrita, mas normalmente, até mesmo quando está compondo seus pensamentos de forma oral. Mais do que qualquer outra invenção individual, a escrita transformou a consciência humana. (ONG, 1998, p. 93)

Nascemos dotados de uma voz que empregamos naturalmente desde os primeiros instantes de nossa existência; o aprendizado da fala também ocorre com naturalidade através da interação com outros seres, ao contrário da escrita, que não surge espontaneamente no sujeito, mas só é adquirida com a intervenção de especialistas, encontrados, na moderna configuração social, na escola. Ou seja, escola é espaço da escrita.

Tratou-se, neste artigo, de traços constitutivos do pensamento e da linguagem que surgem em culturas de oralidade primária; esses contextos possibilitam que os envolvidos no ato de comunicação atuem como sujeitos e participem da vida comunitária, partilhando experiências comuns a todos membros do grupo. Constata-se, assim, que sociedades eminentemente orais valorizam a coletividade e o papel do indivíduo no grupo.

A posição de alguém que fala a outro alguém que lhe responde, por meio da performance típica da oralidade, dá a todos a possibilidade de tornarem-se sujeitos de seus dizeres, quereres, saberes, experiência cuja raridade está trazendo consequiências funestas às sociedades modernas. Como uma das instituições cujo acesso é mais universal, a escola ressente-se dos danos provocados por um sistema que torna sujeitos em objetos e constantemente está em busca de alternativas que a tornem mais eficiente e significativa.

Pois parece-me que, se a escola efetiva e sistematicamente der espaço à voz, sentimentos de pertencimento ao grupo e de afirmação de subjetividade podem tornar-se realidade construída sem nenhum grande aparato ou investimento material. $\mathrm{O}$ investimento a fazer para isso é humano, total e exclusivamente humano; é necessário investir na capacidade inata de falar e de ouvir, de maneira que a condição de sujeito seja alcançada. Se a escola é justamente um dos espaços destinados à construção de sujeitos e de cidadãos,

\footnotetext{
${ }^{6}$ As 'salas de bate-papo', 'chats' e outros meios de comunicação rápida via Internet revelam uma curiosa simbiose entre oralidade e escrita, já que as mensagens são escritas a partir da dinâmica da voz. Essa parece ser uma nova via dos imbricamentos entre entre letra e voz.
} 
não seria o caso de retomar, neste novo milênio, práticas de oralidade e dar voz aos membros da comunidade, professores, alunos e famílias ou cuidadores?

Finalmente, gostaria refletir sobre como as aulas de literatura podem oferecer importante contribuição da redescoberta das qualidades da voz através da circulação da produção oral encontrada em todos os povos. A contação de histórias é uma prática freqüente na pré-escola ou nos primeiros anos do ensino fundamental. Pois que ela seja estendida às séries finais do ensino fundamental e ao ensino médio!

A circulação de textos que guardam marcas de oralidade também podem ser úteis instrumentos para que seja criado e estimulado o interesse pela ficção, pela fantasia, pela linguagem trabalhada artisticamente. No plano temático, a audição ou leitura de contos populares, histórias de cordel, lendas, entre outros, coloca o aluno em universo muito mais familiar do que muitas das leituras literárias que lhes indicamos. E não se trata de oferecer o mais fácil ou simples; narrativas e poemas marcados pela tradição oral têm uma estrutura diferente em relação ao texto escrito porque foram concebidos em contexto diverso, com outros propósitos e amparados por estrutura de pensamento e linguagem bastante peculiar - espera-se que a apresentação dos estudos de Walter Ong e Paul Zumthor feita anteriormente neste artigo tenha deixado isso claro. Por que a escola não refaz o caminho da própria literatura, que tem na voz uma fonte de temas e formas desde o passado até a contemporaneidade?

Mas como a voz pode assumir posição menos subalterna no espaço escolar se os professores não tiverem, em sua formação, contato com a tradição oral? Cursos de Letras, como indica o próprio nome, dedicam-se à escrita e tudo que lhe diz respeito, portanto, manifestações poéticas da voz integram a lista de conteúdos de disciplinas de literatura infantil - isso quando os currículos oferecem essa disciplina. Entretanto, obras e autores canônicos sempre guardam marcas da voz. No caso da Literatura Brasileira, é possível reescrevê-la buscando essas marcas, nem sempre ressaltadas nas análises propostas. Para que o estudo das poéticas da voz integrem a formação dos professores de literatura, é preciso mostrar aos graduandos que há outra forma de ler alguns textos e que é preciso ouvir outros. Assim, refazemos na formação do professor a história da própria literatura, que da voz se fez letra sem jamais deixar de ouvir o eco do som que, entranhado no humano, impele-o ao outro em busca de interlocução.

REFERÊNCIAS:

BERND, Zilá. Fronteiras do literário. Literatura oral e popular Brasil/França. Porto Alegre: Editora da Universidade/UFRGS, 1995.

FERNANDES, Frederico (org.). Oralidade e literatura: manifestações e abordagens no Brasil. Londrina: Eduel, 2003.

ONG, Walter. Oralidade e cultura escrita: a tecnologização da palavra escrita. Campinas, São Paulo: Papirus, 1998.

ZUMTHOR, Paul. A letra e a voz. A "literatura" medieval. São Paulo: Companhia das Letras, 1993. Introdução à poesia oral. São Paulo: Hucitec, 1997. 